\title{
Practical coaching applications for children in the four to six-year-old range: Perspectives from the USTA's American Development Model
}

\author{
Karl Davies, Jason Allen \& E. Paul Roetert \\ United States Tennis Association, USA.
}

\begin{abstract}
The principles discussed in this article have been designed for junior players of all ages and abilities, and therefore, are translational to 10 and under tennis. These are the same principles that are represented in the USTA's American Development Model (ADM). The theory behind the principles will be relayed and then practical applications will be put forward that are pertinent to 4-6-year-olds and speak to long-term athletic development. The overall premise of the ADM is to attract, engage, and retain young players and keep them playing for a lifetime.
\end{abstract}

\begin{abstract}
Key words: 4-6 year olds, long term development, American Development Model.

Received: 22 October 2021

Accepted: 30 November 2021

Corresponding author: Karl Davies.Email: karl.davies@usta. com
\end{abstract}

\section{INTRODUCTION}

The use of modified tennis equipment has been present in the United States for decades. The intensity in its outreach to engage more ten and under players started in conjunction with the ITF's launch of the Play and Stay campaign in 2007 (ITF, n.d.). The United States Tennis Association (USTA) began with a pilot project named $36 / 60$ based on the dimensions of red and orange courts. That pilot became the impetus behind the Quickstart program, which gained some momentum for a few years. Presently, programming that uses modified court sizes and equipment is simply referred to as 10 and Under Tennis (Davies, 2017; Gould et al., 2016).

In 2017, the USTA launched a new youth platform named Net Generation. It presented a solution to the lack of a digital platform for any parent or player to find local tennis programming or instruction (Davies \& Morris, 2018). The value proposition of coaches becoming a Net GenerationCertified Provider had two primary benefits. First, coaches could become SafePlay approved for no cost, which was an unprecedented benefit for parents and players (USTA, n.d.-b). SafePlay approval signified that coaches underwent a background check to ensure they had no criminal history involving children. Second, coaches would have access to a myriad of innovative resources such as curricula, videos, and marketing materials (USTA, n.d.-a).

The application of modified tennis equipment was an integral part of the Net Generation Curriculum (USTA, n.d.-a). Coaches assume different roles and responsibilities based on the audience. Three coach profiles served as the basis for curricular development: industry-certified coaches, community coaches (non-certified), and K-12 teachers (Davies \& Morris, 2018). The purpose of the curriculum was to empower coaches to use modified equipment to attract, engage, and retain diverse

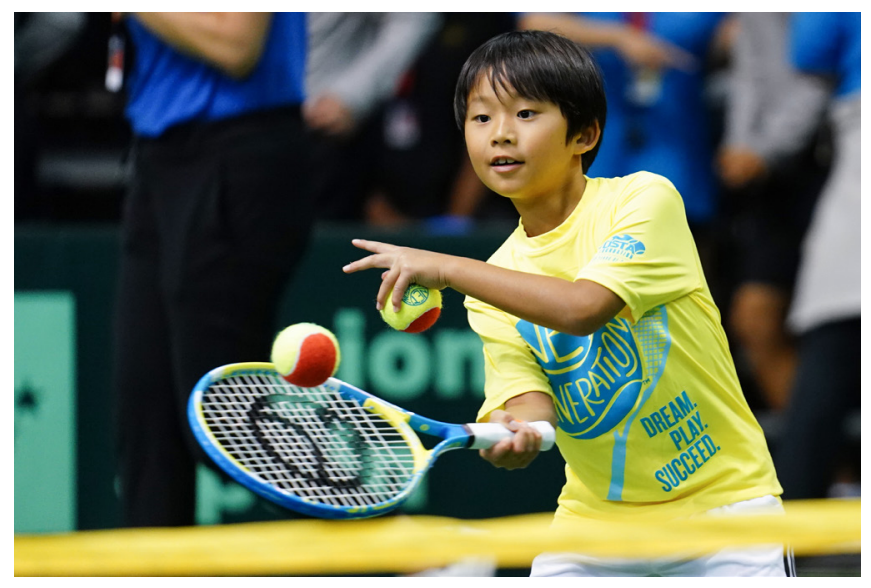

populations and promote lifetime play. The emphasis on modified equipment was predicated on the ITF's evidencebased research findings that highlighted the top 6 benefits of modified equipment: more fun, more success, better learning, smarter tactics, better technique, and safer play (ITF, 2018).

The USTA has always been a proponent of using Long-Term Athletic Development (LTAD) principles in its outreach programs, including competition (Balyi et al., 2013). A USTAappointed task force created a tennis-specific American Development Model (ADM) to make a close connection between LTAD and modified equipment (Davies, 2020). The development of sport-specific ADMs was a United States Olympic and Paralympic Committee (USOPC) challenge issued to National Governing Bodies (NGBs) across the USA. Its guiding principles are age and stage-appropriate development and key definitions to ensure sport-wide continuity (USOPC, n.d.). 
As part of Net Generation, curricula have been created following established competencies for each stage of a modified equipment program. By having competencies for each stage, coaches can guide their athletes as they take their personalized journey to the yellow ball. The use of modified equipment is an influential component of introducing the game of tennis to beginner and intermediate players of all ages for the USTA's ADM. A comprehensive approach was taken when putting the curricula together to engage coaches of all profiles from PE teachers, to non-certified coaches, and certified coaches (USTA, n.d.-a). The progressions in play with modified equipment are also represented in competition. Team competitions are available in all three ball colors with sanctioned tournaments available in orange and green. For developmental reasons, no 10 and under events offer rankings points.

With that being stated, there has been little attention paid to children between four and six. Thus, the purpose of this article is to address the above-mentioned principles of 10 and under tennis-specific to those younger years. The theory behind USTA's ADM will serve as a guide to relay practical applications that equally pertain to these earlier years of entry into tennis. One of the overall premises of the ADM is to attract, engage, and retain younger players by using developmentally-appropriate strategies that will keep them playing for a lifetime. New players between the ages of four and six can also benefit from the ADM's proven methods, but specific considerations must be applied.

\section{PERCEPTIONS OF YOUTH SPORT PARTICIPATION}

Before delving into principles, it is necessary to provide a contextual background of youth sport participation in the USA. In 2018, the USTA's ADM development began by assembling a task force that represented diverse backgrounds. The first step was to invite youth sports expert stakeholders to share insights on what would bring future success to tennis. It quickly became apparent that tennis lacked theoreticallyproven strategies at the beginning stages of a young athlete's journey. The popularity of basketball, soccer, American football, and baseball required tennis, and other sports for that matter, to redesign an approach to ensure growth.

Additionally, four different sport NGBs shared valuable insights. USA American Football, the USGA, USA Lacrosse, and USA Ice Hockey provided much guidance (USA Football, n.d.; USA Hockey, n.d.; USA Lacrosse, n.d.; USGA, n.d.). All four had either completed or were going through the process of creating an ADM. Much value was obtained by understanding the processes undertaken from other sports that were eventually applied to a tennis-driven ADM.

Another valuable stakeholder was The Aspen Institute. During the process of building the tennis ADM, they launched eight groundbreaking principles from their Sport for All, Play for Life Playbook (The Aspen Institute, 2015). The institute felt that these principles, called the 8 Plays, could reimagine youth sport. Three of the Plays resonated with the task force to such a degree that they served as fundamental themes. They were encouraging sports sampling, design for development, and thinking small. As a result of those mentioned above and invaluable stakeholders, the early part of 2019 saw the creation of a tennis-specific ADM that represented a framework for individualized success to support a lifelong love of tennis. The tennis ADM's seven integral principles are universal access and opportunity, multi-sport participation, developmentally-appropriate play, parent education, athlete-centered fun, a clear developmental pathway, and education for coaches and officials. Some of these principles will be addressed in this article and contrasted with tennis participation among four to six-year-old children. Therefore, each section will begin with a theoretical principle from the ADM, followed by a practical applications subsection.

\section{ADM PRINCIPLES AND PRACTICAL APPLICATIONS}

\section{Universal Access and Opportunity}

The concept of universal access and opportunity is a staple of both the ADM and the USTA. As an NGB, the emphasis is on making sure playing tennis is safe, accessible, local, and affordable. The goal is that everyone, regardless of race, color, religion, age, national origin, ability, socioeconomic status, sexual orientation, or gender identity, has access to the benefits of tennis. The aim is to create an inclusive framework for all children to have access and opportunity to experience the benefits of physical activity and be on the pathway to playing the game on their own terms.

\section{Practical Application:}

Successful coaches should be hyper-aware of how to integrate tennis into a younger child's daily physical activities. Finding access and opportunity in the four to six-year-old space can be challenging. But, a great place to start is at local pre-schools and elementary schools (public and private). Most school administrators are open to partnering with local organizations to bring innovative opportunities to students. Community and stakeholder involvement is a crucial element of school and student achievement. Thus, there could be opportunities with the schools to volunteer and help the physical education teacher deliver tennis during one or a series of classes. If there is a before or after school program, that could also be an appropriate avenue. Once a rapport is established with school personnel, tennis-oriented activities could be sent home to parents. Becoming that conduit between the parent and child to provide physical activity through the lens of tennis play and having fun is a beautiful opportunity to showcase how families can play together.

\section{Multi-Sport and Multi-Activity Participation}

The second principle is how young athletes can follow a multisport or multi-activity approach. A multi-sport approach that can include tennis contributes to building athletes in a holistic manner. The mission of the USTA's ADM is to attract, engage, and retain more athletes and keep them playing tennis for a lifetime. Recently, early specialization has become problematic and is symbolic of sport professionalization over the last two decades. A proven solution for developing better athletes at a younger age is to promote sport sampling. Participation in sport sampling has also proven to contribute to better-performing athletes and longevity in physical activity.

\section{Practical Application:}

Kids should be encouraged to play other sports, and parents must be made aware of the benefits of this strategy. Research has identified that kids who participate in multiple sports have increased physical capacity, better motor skills, remain in sports longer, and have a more significant opportunity to build 
social and emotional skills (Roetert et al., 2018). Parents will appreciate a coach being more concerned about their child's holistic development when playing multiple sports. This proven multi-sport approach is how coaches can help children develop appropriately. Incorporating other sports activities in tennis lesson plans such as soccer skills, throwing a football, or dribbling a basketball will increase athletic development and overall fun. This is especially important for children at much younger ages who are still developing in many ways. Tennis facilities can also form partnerships with other sports. Crosspromotion with other programs can engender meaningful coach collaboration opportunities that benefit both the coach and child. Sport specialization, if desired, should ideally occur after the age of 12 and after playing multiple sports (Popkin et al., 2019).

\section{Developmentally-Appropriate Coaching and Play}

Relationship building with the player is crucial for their development. Evaluation and analysis of a new child is a primary first step in quality coaching. Children develop at different rates and times, which requires a basic understanding of growth and development to establish standards of coaching delivery. Even more consideration in four to six-year-olds should be given to this area due to more significant variances in development. In the tennis industry, often, programs are organized by age categories. This is done for the ease of marketing, socialization, and organization. However, two five-year-old children standing side by side will not have the same developmental readiness. There are many factors to understand how coaches should offer developmentallyappropriate coaching to four to six-year-olds, and there is a definite need for more research in this area. Nevertheless, great coaches should emphasize understanding an athlete's developmental level instead of their age. Hence, rapport establishing is a keystone of any great teacher.

\section{Practical Application:}

Due to the even shorter attention spans of children aged four to six, much emphasis should be placed on learning how to promote more engagement. Simple techniques such as using quick transitions, prior organization, high energy, and creative equipment that appeal to younger audiences can be helpful. Seeking more information on differentiation of instruction, multiple intelligences, and emotional intelligences can enhance a coach's ability to pivot to another game plan if breakdowns occur (Dufour \& Marzano, 2011). Ensuring they are engaged and active is crucial to having a great first experience and retaining them in the sport. A great example of sound programming is the Net Generation Red Ball Curriculum for this age category. Six lessons comprise the PreRally unit (USTA, 2017). It is full of activities that guarantee high levels of engagement, are developmentally appropriate, and allow for progressions and regressions. Creative coaches can even further modify some of those activities and use foam balls, which are larger, safer, and easier to hit.

\section{Parent Education}

Parent education aims to provide the information needed to guide healthy and appropriate tennis development. The USTA's ADM website and information within were written with parents in mind. They are vital resources for coaches to further enhance a child's enjoyment, motivation, and overall positive development. The ADM ensures that all information

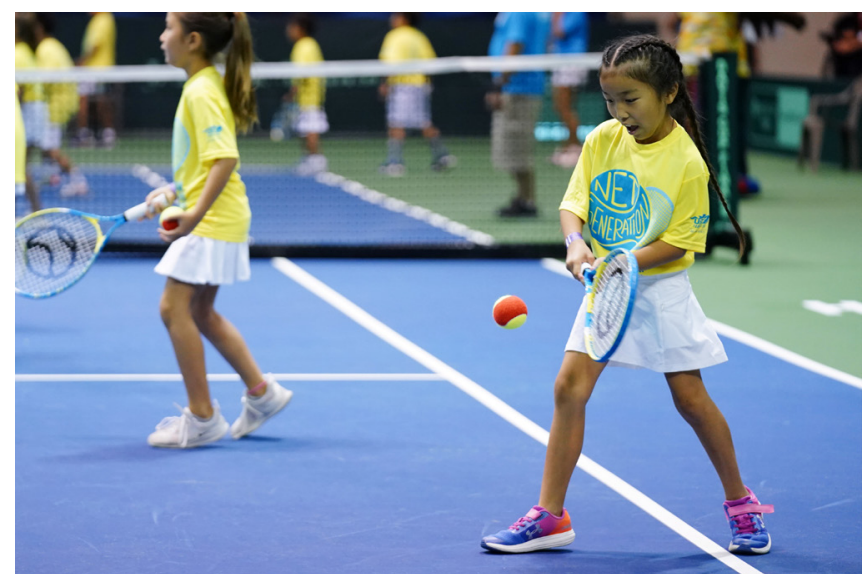

about tennis development is inclusive and accessible through various outlets, including, but not limited to, digital platforms and tennis programming. As the NGB of tennis, it is the USTA's responsibility to share philosophy, directionality, strategic plans, and tools needed to assist diverse communities and to grow the sport of tennis to keep people playing for a lifetime.

\section{Practical application:}

The challenge with parent education is making sure that the information received is both palatable and learner-centered. Parents desire to see their children involved in programs that have a reputation of being the best. Yet, there are few tennis programming options for younger children due to some of the mitigating factors prior stated. Four to six-year-old children have not been exposed to many organized sports programs and, therefore, will still be early in their decision-making regarding what they deem fun. Programming that appears fun, engaging, and cost-effective will be appealing to parents. However, a pamphlet or one-page document explaining the ADM principles will have a powerful effect on a parent's perception of a particular program. It is also recommended to schedule parent meetings that are intended to share information and promote meaningful discussion. During meetings, coaches can also share skill development activities that can be done at home. By showing organization and a desire to communicate with parents, they will indubitably appreciate the extra effort offered by a coach period as it is commonplace for younger-aged programming to be less strategy and theory-based.

\section{Fun and Athlete-Centered}

The ADM emphasizes creating a fun, positive, and engaging atmosphere within an inclusive team culture rather than focusing on wins and losses. The definition of "fun" may change as participants advance in ability and skills, but a standard emphasis on making the process positive and enjoyable is essential. Youngsters also enjoy being team members, so the more they are in groups while participating, the better. At the primary level, in the American public education system, "centers" are a critical part of pedagogy (O'Grady, 2013). Young children will be accustomed to being in groups and moving from one activity to another. Sport commitment models and theory are typically based on developing practical applications to enhance enjoyment (Balyi et al., 2013; Cassidy et al., 2004; Cote et al., 1995; Deci \& Ryan, 2000). The USTA's ADM also aligns with this simple notion. 


\section{Practical Application:}

A practical way to create an environment full of enjoyment in the four to six-year-old space is by simply talking about "fun." Coaches should make constant references to the fun aspects of each part of the lesson. They should also ask the players frequent questions about what is fun. By ascertaining what fun means to the child, coaches can reflect on ways to make subsequent lessons more fun-oriented while still focusing on skill development. Due to their budding and variant levels of cognitive development, they might not know what enjoyment means. Attempts at seeking alternative ways to ask them this information should be part of lesson planning. Another simple suggestion is to ask them what game they would like to play, which enhances relationship building.

\section{CONCLUSIONS}

There is little academic research in coach education and player development for children six years old and younger. However, the ADM for tennis addresses all ages and stages of development along anyone's tennis journey. Therefore, practical ideas were presented in this article to address ways to enhance programming for children between the age of four and six. The central notions presented were universal access to tennis, promotion of playing multiple sports, using developmentally appropriate coaching methods, parent communication and education, and the overemphasis of fun. A final recommendation is for coaches worldwide to create communities of practice to share ideas and best practices. Until there is more empirical research that can be included in coach certification programs to serve this niche age group better, collaboration can prove beneficial for the creation of further best practices.

\section{CONFLICT OF INTERESTS AND FUNDING}

The authors declare that they do not have any conflict of interest and that they did not receive any funding to conduct the research.

\section{REFERENCES}

Balyi, I., Way, R., \& Higgs, C. (2013). Long-term athlete development. Sheridan Books.

Cassidy, T., Jones, R., \& Potrac, P. (2004). Understanding sports coaching. Routledge.

Cote, J., Salmela, J., Trudel, P. \& Baria, A (1995). The coaching model: A grounded assessment of expert gymnastic coaches' knowledge. Journal of Sport and Exercise Psychology, 17(1), 1-17.

Davies, K. (2017). Growing the game, the modified way! ITF Coaching and Sport Science Review, 25(72), 10-11.

Davies, K. (2020). American Development Model for Tennis.

Davies, K., \& Morris, C. (2018). Net Generation: A generation of innovation. ITF Coaching and Sport Science Review, 26(76), 17-20.

Deci, E. L., \& Ryan, R. M. (2000). The "what" and "why" of goal pursuits: Human needs and the self-determination of behavior. Psychological Inquiry, 11, 227-268. https://doi.org/doi:10.1207/S15327965PLI1104_01

Dufour, R., \& Marzano, R. J. (2011). Leaders of learning: How district, school, and classroom leaders improve student achievement. Solution Tree Press.

Gould, D., Pierce, S., Wright, E., Lauer, L., \& Nalepa, J. (2016). Examining expert coaches' views of parent roles in 10-and-under tennis. Sport, Exercise, and Performance Psychology, 5(2), 89-106. https://doi.org/https://doi. org/10.1037/spy0000050

ITF. (n.d.). Play + Stay. Retrieved November 14, 2021, from http://www. tennisplayandstay.com/home.aspx

ITF. (2018). Top 6 reasons to use modified equipment.

O'Grady, P. (2013). Positive psychology in the elementary school classroom. W.W. Norton \& Company.

Popkin, C., Bayomy, A., \& Ahmad, C. (2019). Early sport specialization. Journal of the American Academy of Orthopaedic Surgeons, 27(22), 995-1000. https://doi.org/10.5435/JAAOS-D-18-00187

Roetert, P., Woods, R., \& Jayanthi, N. (2018). The benefits of multi-sport participation for youth tennis players. ITF Coaching and Sport Science Review, 75(26), 14-17.

The Aspen Institute. (2015). Sport for all, play for life: A playbook to get every kid in the game. https://www.aspeninstitute.org/wp-content/ uploads/2015/01/Aspen-Institute-Project-Play-Report.pdf

USA Football. (n.d.). Retrieved November 14, 2021, from https://www. usafootball.com/

USA Hockey. (n.d.). Retrieved November 14, 2021, from https://www. usahockey.com/

USA Lacrosse. (n.d.). Retrieved November 14, 2021, from https://www. usalacrosse.com/

USGA. (n.d.). Retrieved November 14, 2021, from https://www.usga.org/

USOPC. (n.d.). ADM Resources. Retrieved November 3, 2021, from https:// www.teamusa.org/About-the-USOPC/Coaching-Education/AmericanDevelopment-Model/Resources

USTA. (n.d.-a). Net Generation. Retrieved May 26, 2021, from https://hello.usta. com/netgeneration/

USTA. (n.d.-b). Safe Play. https://www.usta.com/en/home/safe-play.html\#/ safeplay

USTA. (2017). Pre-Rally sample plan: Net Generation.

Copyright (C) 2021 Karl Davies, Jason Allen \& E. Paul Roetert

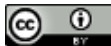

This text is under a Creative Commons BY 4.0 license

You are free to Share - copy and redistribute the material in any medium or format - and Adapt the content - remix, transform, and build upon the material for any purpose, even commercially under the following terms:

Attribution: You must give appropriate credit, provide a link to the license, and indicate if changes were made. You may do so in any reasonable manner, but not in any way that suggests the licensor endorses you or your use. 